\title{
El carácter práctico de la teología
}

\author{
Geraldo de Mori
}

FACULDADE JESUÍTA DE FILOSOFIA E TEOLOGIA, BELO HORIZONTE, BRASIL

Mi contribución en este coloquio es muy simple, pues quiere recordar lo más obvio de la teología -su carácter práctico o su relación con el actuar humano y cristiano-, pero al mismo tiempo problemático, ya que eso, que parece tan obvio, dio origen a abordajes tan diferentes que cuestionan la legitimidad y la cientificidad de la teología práctica. Haré mi presentación en dos momentos: en el primero mostraré algunas dificultades suscitadas por las lecturas que se hace hoy de lo práctico de la teología práctica, indicando la problematicidad de ese campo del saber. En un segundo momento, señalaré lo que me parece fundamental en una reflexión sobre el carácter práctico de la teología.

\section{Lo práctico de la teología y las teologías prácticas}

La primera constatación importante a ser hecha en lo referente a la teología práctica es respecto a la terminología que la identifica. Por un lado, se recurre a los vocablos práctica y pastoral como sinónimos. Es el caso del uso de práctica como sinónimo de pastoral en las teologías prácticas surgidas en el medio protestante a partir de F. Schleiermacher, como lo muestra uno de los últimos manuales producidos en el Brasil por Cristoph SchneiderHarpprecht ${ }^{1}$. Es el caso también del uso de pastoral como sinónimo de práctica en las teologías pastorales surgidas en medio católico a partir de Stepan Rautenstrauch y presentes en los manuales producidos en la línea del Concilio Vaticano II como el de Casiano Floristán ${ }^{2}$ y el de Mario Mi-

\footnotetext{
1 C. Schneider-Harpprecht, Teologia prática no contexto da América Latina (São Leopoldo 1998).

2 C. Floristán, Teología practica. Teoría y praxis de la acción pastoral (Salamanca 1991).
} 
dali ${ }^{3}$. Por otro lado, hay una tendencia a substituir el término práctica por pastoral y viceversa. Es lo que ocurre en buena parte de los estudios de teología práctica surgidos en las últimas décadas en países anglosajones y divulgados en la revista Practical Theology y otras parecidas, y en países francófonos, en el compendio Précis de théologie pratique ${ }^{4}$. Opción inversa, es la del teólogo brasileño Agenor Brighenti, que tiende a substituir el término práctica por el término pastoral ${ }^{5}$.

Los términos práctica y pastoral ciertamente no son sinónimos, como lo muestran las tendencias recientes anteriormente señaladas. Esas opciones indican, sin embargo, que ese campo del saber está todavía en plena construcción, a pesar de haber nacido hace siglos. Este coloquio de teología práctica, organizado por un curso de teología pastoral, es un buen ejemplo de eso. De hecho, el término práctica está relacionado con una dimensión fundamental del ser humano -el actuar- que no tiene originariamente significado religioso o eclesial. En cuanto al término pastoral, tiene su origen en aspectos del actuar cristiano, remitiéndonos de inmediato al cristianismo y a las acciones de sus distintas denominaciones confesionales. En parte, la preferencia por práctica tiene que ver con la búsqueda de cientificidad de las teologías prácticas hechas en ambiente universitario y el énfasis en la pastoral muestra un mayor enraizamiento de las teologías pastorales hechas en diálogo con las comunidades de fe.

Más allá de esa indecisión terminológica, se constatan todavía, en el quehacer teológico, diferentes sentidos dados a los términos práctica y pastoral. En efecto, esos términos son utilizados en la teología por lo menos con cuatro significados distintos: 1) como objetivo para el cual debe ser orientada la formación teológica, identificando la práctica o pastoral con un resultado buscado por la teología; 2) como dimensión que informa el hacer teológico desde el interior, sometiendo lo práctico o pastoral a la teología, y haciéndolo secundario en relación a ella; 3) como determinada disciplina del curriculum teológico, obligatoria, por ejemplo, en las facultades de teología católica, según la Sapientia Christiana, que la denomina teología pastoral, quitando a la práctica o a la pastoral la centralidad

\footnotetext{
3 M. Midali, Teologia pastorale o pratica. Cammino storico di uma reflessione fondante e scientifica (Roma 1985).

4 G. Routhier y M. Viau, Précis de théologie pratique (Bruxelles-Montreal 2004).

5 A. Brighenti, A pastoral dá o que pensar. A inteligência da prática transformadora da fé (Valencia-São Paulo 2006).
} 
que debe poseer en la praxis teológica; 4) como actividades concretas de acción práctica o pastoral (litúrgicas, catequéticas, institucionales, religiosas, sociales, etc.), ilustrando la aplicabilidad de la teología en la práctica o en la pastoral, aludida anteriormente ${ }^{6}$.

Esos distintos significados pueden ofrecer lecturas problemáticas de la teología práctica o pastoral, quitándole la importancia que tiene, tanto en el mundo eclesiástico como en el mundo universitario. Frente a ello, algunos teólogos piensan que la teología práctica o pastoral necesita todavía ser definida y legitimada. Ellos recusan, por ejemplo, su reducción al estatuto de teología aplicada. Esta reducción, presente en las teologías prácticas o pastorales desde la segunda mitad del siglo XX, hace que la práctica o pastoral sea segunda o secundaria en relación con la teología, ya que es vista sólo como transmisión de un saber hacer (¿una técnica?), en general de tipo normativo, cuyo contenido fue producido por la teología. No sé cómo sea vista la teología práctica o pastoral en esta facultad, pero no deja de ser curioso que esta ofrezca un bachillerato en Teología y una licenciatura en Estudios pastorales. Esta última, sería la hermana pobre de la primera o apenas su aplicación, o chay entre ellas una relación de fecundación mutua? Creo que la respuesta a esa pregunta puede llevar a las mismas perplejidades de los teólogos que piensan que el campo de la teología práctica o pastoral necesita todavía ser legitimado ${ }^{7}$. Algunos de ellos añaden todavía que forma parte de esa legitimación la no reducción de la teología práctica o pastoral al ámbito de las comunidades eclesiales, donde esta está encaminada a la predicación, al culto y a la organización interna de las iglesias. Hay que abrirse a nuevos actores, dicen ellos, no solo a los de dentro de la Iglesia, y también a otros campos de la existencia como los culturales, los sociales o los materiales ${ }^{8}$.

Una tercera constatación, al observar las teologías prácticas o pastorales en la actualidad, dice respecto a la perspectiva o al enfoque a partir del cual estas son elaboradas y que, según Jacques Audinet, está en el origen

6 Cf. J. Libanio, «Articulação entre teologia e pastoral. A propósito de uma experiência concreta», Perspectiva Teologica 19 (1987), p. 325-352.

7 Cf. la ponencia de H.-J. GAGEY, «La théologie pratique, quelle rationalité?», en el Coloquio de teología practica del 4-6 de marzo de 2004, llevado a cabo en el Institut Catholique de Paris. Acceso: Revue Theologicum: http://www.catho-theo.net/spip. php?article50.

8 I. Grellier, «Les démarches de la théologie pratique» en B. KaEmpF (Dir.), Introduction à la théologie pratique (Strasbourg 1997). 
de los tres tipos de teología práctica o pastoral vigentes hoy en el escenario teológico: lo empírico, lo crítico y lo fundamental'.

La teología práctica o pastoral empírica está presente, sobre todo, en países anglosajones. Esta ve la práctica como algo empírico, o sea, derivado o guiado por la experiencia. En ese tipo de acercamiento, el término práctica designa la atención a lo real -social o religioso-, accesible a través de los instrumentos de investigación. Se recusa por eso la intuición y la comprensión de la teología práctica como teología aplicada, aunque se valorice los estudios de las mentalidades, de las organizaciones sociales y educativas. La fe y el dato cristiano también forman parte de la investigación que se realiza de modo interdisciplinar y en vistas de una acción. La preocupación pastoral se manifiesta en la intención de dar una formación adecuada y eficiente a los pastores, laicos y comunidades, formación que no se contenta solo con el inmediatismo sino que debe apropiarse de todo lo que las técnicas de relaciones humanas aportaron a la acción de los individuos y grupos. Se invierte por eso en las ciencias humanas, sobre todo en la psicología, en la sociología, en la antropología y en la educación con todo el aparato de procedimientos y métodos de tipo analítico con fines prácticos.

La teología práctica o pastoral crítica busca antes de todo la crítica de las instituciones. Estas son entendidas como el conjunto de formas por las cuales se manifiesta un grupo, o sea, sus organizaciones, sistemas de pensamiento, normas, ritos, discursos, etc. Las instituciones estudiadas son sobre todo de tradición cristiana. No se trata, no obstante, de analizarlas a nivel empírico sino en sus presupuestos. Para ello, se recurre también a las ciencias humanas, pero no para descubrir nuevas técnicas de lo que hay que hacer en la pastoral y sí para mostrar las distorsiones en el funcionamiento de la Iglesia. La categoría de la praxis, reinterpretada distintamente de Marx, es central en ese tipo de acercamiento. Esta ayuda a dar nueva fecundidad y vitalidad a la pastoral como muestran las teologías del mundo, de la liberación, de la secularización, de la negritud y de género, entre otras. Esa perspectiva ha desinstalado a la teología mostrándole que solo podía cumplir bien su misión si se hace inteligencia de la relación entre Iglesia y sociedad. El término práctica, sin embargo, no designa lo empírico de la acción, sino la operación por la cual esta es analizada, teorizada y formulada.

9 J. Audinet, «La diversité pratique des théologies» en J. Doré (Org.), Introduction à l'étude de la théologie 2 (Paris 1992), p. 521-547. 
La teología práctica o pastoral fundamental no se pregunta sobre las formas empíricas de la práctica ni sobre los funcionamientos que las instituyen, sino por la razón de ser de una práctica cristiana. Sus cuestiones principales son: ¿qué significa el cristianismo en cuanto práctica? ¿En qué tiene que ver con la fe cristiana el hecho de que las sociedades actuales se piensen en términos de acción? Y eso no solamente en sus formas recibidas, reconocidas e instituidas a través de la historia, sino en el acto que las engendra, en aquello que las hace existir en cuanto tales en el seno de las sociedades humanas. Esas cuestiones son ineludibles para quien se interroga sobre la práctica, yendo al encuentro de las teorías de la acción y de la sociedad que se multiplicaron en las últimas décadas. Estas no son específicas de la teología práctica sino más bien el bies por el cual esta última se encuentra con la teología fundamental.

Las constataciones hechas anteriormente provocan serios cuestionamientos a la teología práctica o pastoral. ¿Cuál es su identidad? ¿Cómo pensar una relación entre los términos teología y práctica o pastoral, constitutivos, en principio, de esa identidad? ¿A partir de dónde pensar su estatuto epistemológico: de la universidad, lo que implicaría una opción por el término práctica como el más apropiado para decir su identidad, o de la comunidad eclesial, lo que supondría escoger el término de pastoral? Si el carácter funcional parece predominar en varios tipos de teología práctica o pastoral, haciéndola segunda y secundaria en relación al conjunto de la teología, ¿qué se debe hacer para conferirle un carácter eminentemente teológico? ¿Hasta qué punto los varios tipos de teología práctica o pastoral, más allá de su variedad, no son fuente de dispersión y de fragmentación, e inclusive de conflicto en ese campo del saber? Esos cuestionamientos me llevarán a las reflexiones que les propongo en este coloquio sobre el carácter práctico de la teología en general.

\section{El carácter práctico de la teología}

Antes de iniciar mi reflexión, me gustaría decir algo sobre su punto de partida. Como señalé anteriormente, las principales instituciones en las cuales se elabora hoy la teología práctica o pastoral son eclesiales o universitarias. En las primeras, se privilegia el término pastoral y se busca formar, sobre todo, para actividades intra-eclesiales. En las segundas, se prefiere el término práctica y la preocupación principal es el estudio de la acción religiosa en los distintos contextos socioculturales. Así se explica 
el acento interdisciplinar y la preocupación en una formación no solo dirigida a los que ejercen servicios intra-eclesiales ${ }^{10}$.

Más que oponer esos dos lugares donde y a partir de los cuales se hace teología práctica o pastoral hoy, propongo una reflexión de tipo previo o fundamental, necesaria, en mi opinión, para favorecer la fecundación mutua entre esas dos perspectivas. Por ello partiré de un análisis de la práctica como lugar de la teología práctica, y en un segundo momento, reflexionaré sobre el significado de la práctica cristiana y eclesial.

\section{La práctica como lugar de teología práctica ${ }^{11}$}

Buena parte de los teólogos contemporáneos considera que toda teología es o debe ser práctica ${ }^{12}$. Ese tipo de afirmación parece poner en cuestión el lugar de la teología práctica en cuanto disciplina en el corpus teológico. Lo que se afirma, empero, es el carácter práctico de la teología, o sea, su interés por la práctica en cuanto lugar del quehacer teológico. No obstante, ¿a qué práctica se refiere esta definición? ¿Cómo la teología práctica la comprende?

En la filosofía y las ciencias sociales el término práctica designa en general: 1) el actuar humano; 2) un comportamiento estructurado según reglas y formas particulares; 3) un sistema complejo de acción e interacciones, orientado a una finalidad, regulado por reglas de distintos tipos; 4) un conjunto particular de actividades, de un grupo o de un individuo, localizadas en el tiempo y en el espacio; 5) una actividad autorreflexiva que busca aumentar la conciencia de la misma en su contexto y con vistas a una mayor eficacia.

Además de esos significados, el término práctica posee una historia y es objeto de lecturas distintas que deben ser consideradas si se toma en cuenta dicho término para ser pensado en teología.

En la antigüedad griega el verbo prasso significaba: yo actúo, yo hago una actividad, yo realizo algo, y la praxis se refería a casi todas las actividades, especialmente las de carácter público. Estaban sin embargo exclui-

10 G. ADLER, «Questions de théologie pratique dans l'aire francophone catholique» en Revue des sciences religieuses, 69/3, 1995, p. 277-291.

11 El análisis que sigue está inspirado en gran medida en el artículo de J.-G. NADEAU, La pratique comme lieu de la théologie pratique» en Laval théologique e philosophique, 60, 2 (Juin 2004), p. 205-224.

12 W. Kasper, La théologie et l'Église (Paris 1990), p. 22. 
das las actividades corporales, reservadas a los esclavos, para las cuales se usaba el término poiesis. En ese contexto, Aristóteles hizo de la praxis uno de los tres modos fundamentales del conocimiento, al lado de la poiesis y de la theoria.

La tradición marxista distingue práctica y praxis. La práctica es entendida como transformación efectuada por un trabajo humano determinado, con un sentido cercano al de la poiesis aristotélica. La praxis posee un carácter reflexivo y crítico que le da la capacidad de construir la historia. Varios teólogos de la liberación, cercanos a esa tradición, van a pensar en correlación crítica y dialéctica entre la teoría y la praxis, otorgando a la praxis cristiana un carácter liberador y profético en el seno de la historia y de la sociedad ${ }^{13}$. En la actualidad, sin embargo, la distinción entre práctica y praxis es cada vez menos utilizada y los términos práctica, acción y praxis son, en general, vistos como sinónimos. Eso no significa que la comprensión de la práctica sea la misma en las varias teorías elaboradas en las últimas décadas, como las de Alasdair MacIntyre, Pierre Bourdieu, Jürgen Habermas y Paul Ricoeur, entre otros ${ }^{14}$. A continuación, retomaré algunos aspectos de las reflexiones de esos dos últimos filósofos, cuyo pensamiento es referencia en varios proyectos de teología práctica.

Para Ricoeur, las prácticas son «acciones complejas regidas por preceptos de todo tipo, sean estos técnicos, estéticos, éticos o políticos» ${ }^{15}$. Las prácticas, dice él, consisten en cadenas de acciones dotadas de estructuras de carácter: 1) lógico, pues presentan relaciones de coordinación y de subordinación; 2) histórico, pues están insertas en planes de vida y en la unidad de una vida que se desarrolla del nacimiento a la muerte; 3) prescriptivo, pues son regidas por normas y preceptos; 4) ético, pues son marcadas por una dinámica deontológica que implica el respeto al otro. En las prácticas se articulan: 1) los sujetos, con sus objetivos y motivos y los medios que escogen para realizarlos; 2) los resultados de sus elecciones; 3) sus relaciones con otros sujetos, con el tiempo de la

13 C. Boff, Théorie et pratique : la méthode des théologies de la libération (Paris 1990).

14 A. Macintyre, After Virtue. a study in moral theory (Notre Dame 1984); P. Bourdieu, Le sens pratique (Paris 1980); P. Ricoeur, Du texte à l'action. Essais d'herméneutique II (Paris 1986); J. Habermas, Théorie de l'agir communicationnel (Paris 1982).

15 P. Ricoeur, «Les structures téléologiques et déontologiques de l'action: Aristote et/ ou Kant?» en J.-G. NADEAu (Org.), L'interprétation, un défi à l'action pastorale (Montréal 1989), p. 15. 
existencia y las circunstancias que no escogieron, pero que determinan su actuar y su padecer. Además de esas características, Ricoeur propone la distinción entre práctica y praxis, situando la primera en la escala de la segunda, que comporta cuatro niveles: 1) los prácticos; 2) el plan de vida, al cual las prácticas son articuladas o referidas; 3) la unidad narrativa de la vida, que las capta e integra en una historia; 4) el deseo de una vida buena y realizada.

Habermas, en su teoría de la acción comunicativa, distingue cuatro tipos de actuar: 1) El teleológico: se especifica a partir de los cálculos de utilidad y es caracterizado por la relación entre medios y fines. Los criterios de ese actuar tienen que ver con el conocimiento del mundo objetivo y exterior y con la eficacia con que en él intervenimos; 2) El normativo: se refiere a los valores comunes en función de los cuales los miembros de un grupo orientan su acción. La obediencia a una o varias normas es ahí central. Los criterios de base de ese tipo de actuar son la legitimidad de las normas y la conformidad que con ellas tienen las acciones; 3) El dramatúrgico: hace que los participantes de las acciones constituyan un público uno para el otro. El concepto central ahí es el de representación o expresión de sí y los criterios de base son la veracidad y la autenticidad de la comunicación con relación al mundo subjetivo interno; 4) El comunicativo: implica una perspectiva moral opuesta a la únicamente performativa o utilitaria. Ese tipo de acción está relacionado con la búsqueda de entendimiento y de consenso entre los sujetos. Para eso, es importante el concepto de interpretación, que consiste en hacer entrar en el propio punto de vista el del otro.

Como se puede notar, el término práctica es objeto de una diversidad de acercamientos. Algunos subrayan el aspecto sistémico, objetivando las prácticas y haciendo del sujeto un elemento entre otros. Otros acentúan el aspecto práctico, situando al sujeto reflexivo en el centro de las prácticas. A la luz de esa polaridad, propondremos a continuación, los principales rasgos de una reflexión fundamental sobre la práctica, la praxis o el actuar humano.

\section{La práctica como sistema complejo}

La práctica, como vimos en Ricoeur, es un sistema complejo de acciones e interacciones de sujetos, que implican objetivos, son reguladas por distintas normas, remiten a motivos o a agentes que, al mismo tiempo, hacen 
o pueden hacer cosas consideradas como sus obras. Las consecuencias de esas acciones tienen a sus agentes como responsables. Ellos actúan y sufren en circunstancias que no produjeron, pero que pertenecen a su campo práctico y buscan influenciarlo. Además, actuar es siempre actuar con otros, y eso puede darse como cooperación, competición o lucha ${ }^{16}$. Es por eso que el sistema de acción constituye un primer objeto del estudio de las prácticas, que puede ser realizado a través de la semántica de la acción, enunciada en las frases de acción: ¿Quién hace qué, dónde, cuándo, cómo y por qué? En ese sentido, para comprender el término agente es preciso situarlo correctamente en la red de la acción, cuyos elementos están en una relación de intersignificación.

\section{La práctica como inscripción y compromiso de sujetos}

Definir la práctica como un complejo de acciones voluntarias y orientadas a una finalidad es afirmar que es portadora de la perspectiva de un sujeto que puede ser colectivo o individual. Por ello, el sujeto es el principal objeto de las prácticas y de una teología práctica que, como veremos en la segunda parte, se ocupa de las diferentes dimensiones a partir de las cuales se edifica la existencia humana. Los sujetos en cuestión son: 1) corporales, afectivos, espirituales, y sensatos; 2) agentes y pacientes; 3) marcados por necesidades y deseos; 4) capaces de juzgar y escoger; 5) articulan recursos y acciones con objetivos; 6) en función de ideologías, de representaciones del mundo, de sí mismos, de la vida y del universo; 7) en contextos diversificados e imbricados, que los influencian y determinan en gran parte sus representaciones, elecciones, decisiones y acciones.

No existe por tanto, práctica sin sujeto, aunque lo contrario también es verdadero, no existe sujeto sin práctica. En general, el es sujeto de la acción con otros. En ese sentido, la práctica o lugar de compromiso del sujeto con el mundo, el lugar de comprensión y de elaboración de sí y del mundo, es el lugar de autentificación y de conversión del discurso y del ser. Podemos decir que en ella se desvela y se transforma el sujeto y el mundo ${ }^{17}$. Es a través de ella que se elabora el sentido, la identidad del sujeto y de su relación con el mundo y con lo Absoluto, la identidad de la colectividad y de la ética.

\footnotetext{
16 P. Ricoeur, Temps et récit 1 (Paris 1983) p. 88-89.

17 D. Tracy, The Analogical Imagination: Christian theology and the culture of pluralism (New York 1989).
} 


\section{La práctica como acto de interpretación}

La hermenéutica de las prácticas es fundamental en la teología práctica, tanto para dejar emerger las interpretaciones o los sentidos presentes en la práctica, cuanto para criticarlos. Por ello esta es también una dimensión fundamental de las prácticas. En realidad, la práctica es un acto de interpretación que cada uno ejerce, en primera persona, al situarse delante del mundo y de otros con cierto proyecto de acción. En ese acto de interpretación, esta es indisociable de la teoría y de la ética. Realizada en general, por varios actores o sujetos, la práctica supone una pluralidad de interpretaciones, que muchas veces es fuente de conflictos. ¿Qué interpretación privilegiar al analizarla? El proceso hermenéutico, como propone Ricoeur, o la acción comunicativa, como lo propugna Habermas, puede ayudar a determinar qué visión, qué narrativa y qué metáfora corresponden mejor a los datos del mundo, a los deseos de los actores en su contexto y con sus desafíos, y a la práctica que parece más verdadera, más liberadora, o la que más contribuye para el proceso de humanización.

\section{La co-implicación del sujeto y del sistema}

En la práctica, sujeto y sistema se co-implican. Por un lado, el sujeto es un elemento del sistema que lo determina. Por otro, él busca inscribir algo de sí en el sistema. Esta co-implicación es vivida como tensión, porque la práctica nunca corresponde plenamente al deseo o al ser del sujeto ya que al traducirlo en lo real esta lo despoja de sí, o en ciertos casos, lo aliena de sí. En ello esta muestra su carácter dramático o trágico.

\section{La práctica como poder del actuar}

A pesar de ese carácter dramático, toda práctica conlleva cierta representación de un poder actuar por parte del sujeto o de su capacidad de hacer algo. En ese sentido actuar implica la conciencia de un poder actuar. Esta conciencia, según Ricoeur, es previa a la acción y es supuesta cuando digo yo puedo. Sin ella no existe práctica en el sentido estricto, es decir, voluntaria o consciente. Tampoco existe estima de sí y ética, ya que esta solo existe para los seres capaces no solo de auto-designarse como locutores, sino también como agentes de su acción, por tanto, responsables y, por eso, imputables éticamente ${ }^{18}$.

18 P. Ricoeur, «Approches de la personne» en Esprit, 160 (Marzo-Abril 1990), p. 126. 


\section{La práctica como interacción asimétrica}

La práctica, como dijimos, es lugar de competición, de lucha, de dominación, de sumisión, de intercambio y de cooperación. A través de ella se construye el poder que, y así y todo, no es compartido igualmente en la sociedad. La acción se muestra, por ello, marcada por una desigualdad estructural o por una disimetría entre agente y paciente. Actuar es siempre intervenir sobre, aunque por persuasión, y no solamente intervenir con. El otro puede, por ello, tornarse victima de mi acción ${ }^{19}$, reducido a instrumento o a medio. No se puede, por ello, idealizar la acción, ya que el conflicto y la sujeción siempre la amenazan y la atraviesan. En la Iglesia, infelizmente, hay una fuerte tendencia a la idealización de la acción, en nombre del respeto, de la benevolencia, del amor y del perdón que siempre estamos llamados a dar al otro, lo que impide muchas veces la real conversión de nuestra relación con el poder.

\section{La práctica como comunicación}

La práctica es también lugar de comunicación. Su eficacia supone la comunicación entre los agentes de la acción. Actuar es decir y cambiar algo de sí, de su visión del mundo y de sus deseos con otros individuos o grupos. Como bien lo mostró Austin, decir es hacer ${ }^{20}$. Ahora, lo contrario también es verdad, o sea, hacer también es decir. Existe por tanto una implicación recíproca entre el hacer, el actuar y el decir. Poner eso en evidencia es el primer desafío de una hermenéutica de la praxis. De hecho, el lenguaje no sirve solo para representar el mundo, sino para orientarse en él, construyéndolo a través de acciones. Como lo sugiere Ricoeur, la acción puede ser leída como un texto. Retomando la tipología de Searle, él indica algunos rasgos de la acción como texto: 1) asertivo: por la pretensión que la práctica, sobre todo, la de intervención, tiene a la verdad; 2) directivo: pues la práctica es orientada a la acción y pone a los agentes en movimiento; 3) comisivo: una vez que esta implica un compromiso en aquel que la realiza o la asume; 4) expresivo: ya que la práctica es el lugar donde el ser humano exprime lo que él es con sus posibilidades y límites; 5) declarativo: pues la práctica realiza lo que ella pretende; 6) comunicativo: pues la práctica es un pedido de reconocimiento y un lugar de intercambio de reconocimiento.

\footnotetext{
19 P. Ricoeur, Les structures téléologiques et déontologiques de l'action, op. cit., p. 24.

20 J. Austin, Doing Things with Words.
} 


\section{La práctica como obra abierta}

Si la acción puede ser leída a la luz del modelo de texto, podemos considerarla también como obra. De hecho, esta comporta un sentido que le viene de sus agentes y de un sistema que, en general, es identificado como contexto. Como ocurre con el texto, también la práctica se destaca del evento y de sus actores. Esta no necesariamente realiza su intención y muchas veces la supera. Por su carácter público, por sus diferentes agentes y por la co-implicación de estos con el sistema la acción es lugar de una multiplicidad de interpretaciones, que no tiene sentido único ni definitivo sino abierto. Esta deja vestigios en la historia, cuyo destino escapa a sus actores. Por eso, su significado no coincide con las intenciones de sus agentes, sino que reside en la práctica misma. Como el texto, la práctica se abre a quien quiera que sepa leer, pudiendo recibir interpretaciones distintas, inclusive de sus actores. En ese sentido, la acción abre o cierra un mundo de posibilidades. Así, la teología, y en particular la teología práctica, se coloca delante de esas posibilidades de ser y de actuar abiertas por la práctica de Jesús e intenta reactualizarla de nuevo en los diferentes contextos y épocas.

\section{El significado de la práctica cristiana y eclesial}

El análisis fenomenológico fundamental que hicimos del término práctica tiene implicaciones en todas las dimensiones o ámbitos de la existencia y de la acción humanas, desde los más elementales, como el económico y el sociopolítico, hasta los más elaborados como el ético, el filosófico y el religioso. La práctica y el actuar cristianos se inscriben, por tanto, en el seno de esas dimensiones o ámbitos. Así, para el conjunto de la humanidad, la mejor respuesta que los cristianos deben dar a las preguntas ¿qué debo hacer? ¿cómo actuar? ¿cuál es la mejor práctica? es hacer el bien para que la vida sea buena para todos y para cada uno ${ }^{21}$.

Por tanto, las prácticas cristianas se encaminan también hacia la vida buena para todos y cada uno, y en todas las dimensiones o esferas de la existencia y de la acción humanas. Esto sucede a partir de las prácticas de Jesús y de la praxis divina del Dios que él anunció y reveló como Buena Noticia y Abba. De hecho, en la predicación de la Iglesia primitiva, Jesús es presentado como aquel que «pasó haciendo el bien» (Hechos 10,38). Y él lo hace curando, alimentando, liberando los cuerpos, corazones y espí-

21 P. Ricoeur, Soi-même comme un autre (Paris 1990), p. 202s. 
ritus de diversas maneras y en diferentes situaciones (Lucas 7,21, Marcos 6,30 a 44). Él hace el bien expandiendo el proyecto de «reunir en la unidad a los hijos e hijas de Dios dispersos» (Jn 11,52), reintegrando en la comunidad de la salvación a los que ciertas lecturas de la ley tendían a excluir (Lucas 19,1-10; Jo 7,53 a 8,11). Jesús hace el bien abriendo el campo filial en relación con Dios, porque él es el Hijo que, por la Pascua, hace accesible la filiación a todos, y el campo fraterno en relación a los otros, ya que él es el «primogénito de muchos hermanos y la cabeza de un cuerpo con dimensiones universales» (Ef 1,10).

Las prácticas cristianas suponen por tanto que, en el seguimiento de Jesús, los discípulos de ayer y hoy también curen, alimenten y liberen, conduciendo la humanidad a la filiación y a la fraternidad. Esta perspectiva es llamada a hacerse realidad en diferentes dimensiones o ámbitos en los que la práctica humana se lleva a cabo: económico, sociopolítico, ético, filosófico y religioso. Veamos qué significado adquieren allí las prácticas cristianas.

\section{Pan compartido o la dimensión económica de las prácticas cristianas}

La primera pregunta de la práctica tiene que ver con la vida, que necesita de la dimensión económica -comer, beber, vestirse, etc.- como una de sus dimensiones constitutivas. En el Evangelio de Mateo, una práctica asociada con esta dimensión se expresa en términos de la salvación: «Tuve hambre y me disteis de comer, sediento y me disteis de beber, estuve desnudo y me vestisteis» (Mt 25,35-36). Lo que ahí es dicho en singular se puede expresar colectivamente, es decir, la salvación concierne a la economía en la complejidad de la producción y el consumo de bienes y servicios, y en la manera de cómo se comparte para que todos y cada uno vivan bien.

Por ello, las prácticas cristianas no pueden ignorar la dimensión económica, pues en ella se juega la vida y la supervivencia de todos y de cada uno. El problema de la fraternidad universal, que tiene connotaciones religiosas y políticas, es también un problema económico, y se traduce como una cuestión de pan compartido. En los Evangelios este asunto es fundamental, como lo demuestran los episodios de los panes (Mc 6,3044, Mt 14,13-21, Lc 9,10-17; Jn 6,1-15). Antes de ser un tema eucarístico, se trata de un tema económico y permanece tal incluso cuando se hace eucarístico. Esto significa que no es posible dar cuenta de la fe y de la 
práctica cristianas, sin integrar a la práctica del compartir simbólico del pan eucarístico la práctica concreta de pan económico. Las primeras comunidades cristianas, que llevaban a la celebración eucarística pan para ser compartido con los más pobres, ya lo habían entendido. Con el tiempo, todo esto se expresará en términos de justicia.

La cuestión económica también da lugar a la codicia, a los conflictos y a las guerras, ante los cuales la fe cristiana tiene que resistir con la práctica del pan compartido y la práctica de la justicia.

\section{Elpoder compartido o la dimensión sociopolitica de las prácticas cristianas}

La cuestión del poder también se encuentra en el corazón de las prácticas humanas. Es la cuestión política por excelencia y que, en la historia humana ha sido una fuente de la codicia y llevó a numerosas guerras en todos los medios y en todas las épocas. En los Evangelios, los discípulos le preguntaron a Jesús: «¿Quién es más grande?» (Mt 18,1s, Mc 9,33-37, Lucas 9,46-48), a lo que responde colocando a un niño en medio de ellos e invirtiendo la cuestión de los lugares: el que sirve es el más grande (Jn 13,1s). Respuesta revolucionaria, que supera todas las revoluciones en la historia. Poner en primer lugar a los pequeños y pobres es tan contrario al buen sentido político y a la praxis social habitual que nunca encontró un lugar donde poder manifestarse, que sigue siendo una utopía. Pero esta utopía está todavía presente en el corazón de las prácticas cristianas como una contestación permanente de formas de construir la sociedad y de ejercer el poder. Socialmente eso significa hacer una sociedad mediante el establecimiento de instituciones justas y normas que hagan que todos y cada uno encuentren su lugar y sean reconocidos. Se trata de un vasto proyecto que se reinicia siempre y que supone un constante proceso de conversión de las prácticas.

\section{El bien y el amor compartido o la cuestión ética de las prácticas cristianas}

En el Evangelio de Lucas, un escriba hace una pregunta radical a Jesús: «¿Qué debo hacer para tener vida eterna» (Lucas 10,25s). La respuesta de Jesús es sorprendente: «¿Qué dice la ley? ¿Cómo la lees?» El escriba respondió brillantemente: «Amarás al Señor tu Dios con todo tu corazón y con toda tu alma y con todas tus fuerzas y toda tu mente ... y al prójimo como a ti mismo». Al ser elogiado por Jesús, él responde: «ن Y quién es mi prójimo?» Jesús responde con la parábola del Buen Samaritano, mostran- 
do que la práctica con valor de eternidad es la que se da en la vida cotidiana, con los que se encuentran en la orilla del camino. No hay otro lugar y tiempo para la utopía y la eternidad, sino el aquí y ahora donde estamos.

La práctica y la ética son remitidas a lo cotidiano, según las situaciones, pero siempre con miras a la renovación, transformación y conversión, para que la vida sea mejor para todos. En este sentido, las prácticas cristianas son las de hacer el bien, de modo que cada uno encuentre el bienestar. Se trata de un vasto emprendimiento, que tiene las medidas del Reino de Dios, y para ello debemos revisar y renovar incesantemente lo que está en juego en las prácticas humanas para que todos se sientan hijos e hijas de Dios, hermanos y hermanas entre sí. En el Evangelio de Marcos, cuando el escriba dice que el amor a Dios y al prójimo vale más que todos los holocaustos y sacrificios», Jesús responde que no está lejos del Reino de Dios (Marcos 12,28-34). Estar cerca del Reino de Dios es saber darse cuenta de que amar a Dios y al prójimo vale más que todos los sacrificios y holocaustos. Esto es revolucionario en el universo religioso, que tiende a dar prioridad a los holocaustos y sacrificios de todo tipo. La carta a los Hebreos dice lo mismo: «No te olvides de hacer el bien y compartir, porque estos son los sacrificios que agradan a Dios» (Hebreos 13,16). Pablo también lo dice magistralmente: el amor (ágape) relativiza cualquier otro carisma, ministerio, magisterio o función (1 Corintios 13,113). Infelizmente, en la práctica histórica somos tentados a relativizar la praxis-ágape y no creer en su eficacia económica, sociopolítica y ética. Creemos más fácilmente en los dioses político-religiosos que proponen la violencia como salvación, antes que el amor concreto a los hermanos y hermanas en situaciones adversas y complejas. Pero solo el ágape puede hacer posible el paso entre el pensamiento y la acción, transformando la teoría en práctica.

\section{La verdad y el sentido compartidos o la dimensión filosófica de las prácticas cristianas}

La teoría es fundamental para la práctica. En una perspectiva cristiana, se somete a la voluntad de Dios o a la práctica de Jesús, que vino a predicar el Reino de Dios. La práctica cristiana se resume teóricamente en un llamado a realizar las peticiones del Padre Nuestro: «Venga a nosotros tu reino» y «Hágase tu voluntad» (Mt 6, 9s, Lucas 11,2-4). La búsqueda de la verdad y del sentido consiste en descubrir y realizar el Reino de Dios. En el Evangelio de Lucas, Jesús responde a los enviados de Juan el Bautista que le preguntan si él es el que habría de venir y si deben esperar a otro, 
mostrándoles lo que él acababa de hacer: «Los ciegos recuperan la vista, los paralíticos caminan, los leprosos quedan limpios, los sordos oyen, los muertos resucitan y a los pobres se le anuncia la Buena Nueva...» (Lc 7, 22). Este actuar de Jesús es lo que salva. En él se revela la salvación, por eso el actuar de Jesús se constituye la sabiduría de Dios revelada a los pequeños (Mt 11.25-26, Lucas 10:21), los mismos pequeños que son los primeros en beneficiarse de las prácticas benevolentes o las víctimas de las prácticas violentas.

\section{La filiación y la fraternidad compartidas o la dimensión religiosa y eclesial de las prácticas cristianas}

A las preguntas religiosas ¿quién es Dios?, ¿qué relación bay entre ély nosotros?, la fe cristiana responde diciendo que Él es una comunión de amor-Padre, Hijo y Espíritu Santo- y que una relación particular de filiación en y con el Hijo demanda una fraternidad potencial y escatológicamente universal con todos y cada uno. La Iglesia, pueblo de Dios, cuerpo de Cristo y templo del Espíritu Santo es, de modo sacramental, ese proyecto de filiación y de fraternidad universal, cuyo objetivo es «reunir en la unidad a los hijos de Dios dispersos» (Jn 11,52). Este proyecto, inscrito en el corazón de la tradición cristiana como un proyecto eclesial, es llamado a ir al encuentro de las otras tradiciones religiosas, para que se cumpla la gran utopía de filiación y de fraternidad universales.

Desde esta perspectiva, la práctica eclesial primera y fundamental es la de ser, en la práctica, ese pueblo de Dios, ese cuerpo de Cristo y ese templo del Espíritu Santo que vive la filiación y la fraternidad universal. Esta práctica está relacionada con todo lo que dijimos acerca de las otras dimensiones de la práctica. Esto no impide, sin embargo, que surjan prácticas propiamente eclesiales, como las liturgias o sacramentales, y en particular las bautismales y las eucarísticas. El bautismo, con la relación que tiene con la eucaristía, es el rito fundador del cristianismo y de toda práctica cristiana. Es celebración de la filiación, donde los bautizados son sumergidos con Cristo en su muerte y revivificados en su resurrección. Es la celebración de la filiación y la llamada a reconocerla en la práctica, viviendo la fraternidad.

La práctica de los cristianos se enraíza en el hacer memoria eucarística: «Haced esto en memoria mía» (Lc 22,19, 1Cor 11,24-25). De hecho, todo el actuar cristiano es un hacer memoria del Crucificado-Resucitado. El 
«haced esto en memoria mía» conduce a un hacer como Jesús: «Amaos los unos a los otros como yo os he amado» (Jn 15,12) o un hacer como Dios que «hace salir el sol para buenos y malos y da la lluvia a los justos e injustos» (Mt 5,45), o ser misericordioso y perfecto como el Padre (Lucas 6:36, Mateo 5,48). La praxis memorial se convierte en una praxis del seguimiento que lleva a hacer lo que él hizo. El Espíritu es el que la hace realidad (Jn 14,26), animando a la Iglesia, vivificando el mundo y acudiendo en ayuda de los fieles para que puedan gritar: ¡Abba, Padre (Rom 8,15).

\section{El más allá de la muerte o la contestación de la muerte: la dimensión cristiana de las prácticas cristianas}

Lo que hace que las prácticas cristianas sean cristianas es Jesús, el Cristo. Ellas serán cristianas en la medida que sean marcadas por aquello que aconteció con él. Jesús anunció el Reino de Dios (Marcos 1,15), pasó haciendo el bien (Hechos 10,38), fue rechazado (Jn 1,11), tomado preso, condenado, crucificado, muerto, pero «Dios le levantó liberándolo de las garras de la muerte» (Hechos 2,24). Su resurrección es la praxis vivificante por excelencia, aquella que revoluciona toda praxis. Es la gran praxis divina: «Dios hizo Señor y Cristo a este Jesús a quien vosotros habéis crucificado» (Hechos 2,36). La palabra de Dios, proferida en el bautismo y en la transfiguración: «Este es mi Hijo amado» (Mt 3,13-17, Mc 1,9 a 11, Lucas 3,21-22, Mt. 17,1-9, Marcos 9,2 a 10, Lucas 9,28-36), es su praxis de amor, que triunfa sobre la violencia y la muerte. La cruz, un instrumento de tortura, de violencia y de muerte, no tiene la última palabra. A partir de entonces, todas las cruces ya no son la última palabra. Dios, que es amor, tiene y tendrá siempre la última palabra. Él es el primero y el último de la praxis cristiana. Lo que los cristianos creen por la fe, ellos lo traducen en sus prácticas, que son también llamadas a la audacia pascual.

\section{Conclusión}

Las ideas que acabamos de esbozar necesitan ciertamente ser más desarrolladas, para que su contenido pueda realmente aparecer con mayor clareza y profundidad. Quisimos mostrar con estas el significado del carácter práctico de la teología. Este carácter es constitutivo del quehacer teológico en cuanto tal, y no un apéndice o una mera aplicación de un saber elaborado sin ninguna relación con el suelo vivo en el cual la vida se plasma, acontece y alcanza sentido. 
Como se puede notar, todos los ámbitos de la práctica están implicados en esta forma de pensar la práctica. Es necesario pensar los desdoblamientos de lo que dijimos anteriormente en los distintos tratados teológicos. Con ello no queremos teorizar la práctica, sino mostrar su estatuto en la existencia humana y en la teología. Sin embargo, queda un largo camino por recorrer. Creo que la teología de la liberación, como fue mostrado en sus principales teóricos de América Latina presentados en este coloquio, ya dio grandes pasos en esa dirección. Nos corresponde a nosotros dar seguimiento a la labor por ellos iniciada y continuada por tantos otros, llevando en cuenta los nuevos contextos en los cuales vivimos y los nuevos datos de los estudios sobre la práctica hoy día propuestos. Ojalá este coloquio nos inspire en ese sentido, para que la teología hecha en nuestro continente continúe contribuyendo para que el actuar de los cristianos de América Latina sea realmente el de los testigos del actuar de Jesús de Nazaret y de tantos que le siguieron e imitaron a lo largo de los siglos. 
Resumen: Este artículo evidencia cómo lo práctico es un elemento eminentemente constitutivo del quehacer teológico. Este aspecto práctico, obvio para la teología -en la tesis del presente estudio-, se presenta como problemático, pues ha dado origen a puntos de entrada tan diversos, que finalmente cuestionan la legitimidad y cientificidad de la teología práctica.

Palabras clave: Teología práctica, pastoral fundamental, praxis cristiana.

Abstract: This article shows how the practical aspect is a fundamental constituent of the theological endeavor. Such practical aspect, which is obvious for theology as stated in the thesis of this study, is portrayed as being problematic since it has given rise to entry points so diverse that, in the end, they question the legitimacy and scientificity of practical theology.

Keywords: Practical theology, fundamental pastoral theology, Christian praxis. 
